\title{
Teaching a discrete information technology course in a constructivist learning environment: is it effective for Malaysian pre-service teachers?
}

\begin{abstract}
The purpose of this research was to measure pre-service teachers' attitudes toward information technology (IT) following their participation in a discrete IT course. The IT course was taught in a constructivist learning environment where the students collaborated to achieve their learning goals and problem solve on tasks [Educ. Technol. 35 (1995) 25]. The results of the study revealed that with the constructivist learning approach infused in the IT course, there was a positive shift in the participants' attitudes toward IT. Pretest results showed that participants who were competent had regarded IT as more useful; and they had more confidence and less aversion toward technology. The posttest results showed increased mean scores on all three dependent variables (e.g., usefulness, confidence, and aversion) with no differences between competent and incompetent participants by the end of the course. The responses obtained from interviews of course instructors indicated that participants were more independent, more creative, and used their collaborative learning skills. While an exploratory study, the results provide support for the premise that infusing constructivism into a discrete IT course can enhance positive attitudes towards IT and enable students to be active participants in their own learning process.
\end{abstract}

Keyword: Constructivist learning environment, Discrete IT course, Pre-service teachers 